\title{
STABILITY OF SHEET FLOW OF WATER BENEATH TEMPERATE GLACIERS AND IMPLICATIONS FOR GLACIER SURGING
}

\author{
By JoSEPH S. WALDER* \\ (Department of Geology, Stanford University, Stanford, California 94305, U.S.A.)
}

\begin{abstract}
A mathematical model is presented for the stability of sheet flow of water beneath a temperate glacier. Enhanced viscous heat dissipation in thick parts of the sheet tends to make sheet flow unstable, the instability increasing as sheet thickness and pressure gradient increase. However, incipient channels may be destroyed as the glacier slides over protuberances on its bed. Quasi-stable sheet flow may be possible for sheets up to several millimeters in thickness, especially beneath glaciers that have relatively gentle surface slopes and slide at moderate to high speeds. Such water sheets may somewhat reduce the effective roughness of glacier beds, but probably not enough to allow surge initiation. Furthermore, the presence of numerous water-filled cavities at the glacier bed will tend to reduce the sheet thickness and lessen the degree of "lubrication" of the glacier bed by the water sheet.
\end{abstract}

RÉSumÉ. Stabilité d'un écoulement en nappe d'eau sous des glaciers tempérès et conséquences sur les débâcles glaciaires. On présente un modèle mathématique pour la stabilité d'un écoulement en nappe d'eau sous un glacier tempéré. La dissipation de chaleur par viscosité dans les parties épaisses de la nappe tendent à rendre l'écoulement en nappe instable, l'instabilité croissant lorsque l'épaisseur de la nappe et le gradient de pression s'accroissent. Cependant les chenaux affluents peuvent être détruits par le glissement du glacier sur les protubérances de son lit. Un écoulement en nappe quasi-stable est possible pour des nappes allant jusqu'à plusieurs millimètres d'épaisseur, spécialement sous les glaciers qui ont une pente de surface relativement modérée et glissent à des vitesses modérées à fortes. De telles nappes d'eau peuvent parfois réduire la rugosité efficace des fonds rocheux, mais probablement pas assez pour permettre le début d'une crue rapide. De plus, la présence de nombreuses cavités pleines d'eau sur le lit glaciaire tendra à réduire l'épaisseur de la nappe et de minimiser le degré de "lubrification" du lit glaciaire par la nappe d'eau.

Zusammenfassung. Stabilität des Schichtflusses von Wasser unter temperierten Gletschern und Auswirkungen auf Gletscherausbrüche. Für die Stabilität des Schichtflusses von Wasser unter temperierten Gletschern wird ein mathematisches Modell vorgelegt. Erhöhter viskoser Wärmeaustausch in dickeren Teilen der Eismasse verursacht Instabilitäten im Schichtfluss, die mit wachsender Eisdicke und wachsendem Druckgradienten zunehmen. Immerhin können neu gebildete Kanäle zerstört werden, wenn der Gletscher über Höcker auf seinem Bett gleitet. Ein quasistabiler Schichtfluss kann sich für Schichten bis zur Dicke von einigen Millimetern ausbilden, besonders under Gletschern mit relativ sanfter Oberflächenneigung und mässiger bis hoher Gleitgeschwindigkeit. Solche Wasserschichten können die effektive Rauhigkeit des Gletscherbettes um einiges verringern, vermuthlich jedoch nicht genug, um einen Ausbruch zu verursachen. Des weiteren kommt es durch das Vorhandensein vieler wassergefüller Hohlräume am Gletscherbett zu einer Verringerung der Eisdicke und zu einer Abnahme der "Schmier"-Wirkung der Wasserschicht auf das Gletscherbett.

\section{INTRODUCTION}

The mode of flow of water at the beds of temperate glaciers has been of considerable interest to glaciologists, particularly because of apparent relationships between subglacial hydrology and temporal variations in sliding velocity (e.g. Weertman, 1972, p. 288-89; Hodge, 1974, 1979; Röthlisberger and others, 1979). A number of recent field studies of existing glaciers have yielded important data on subglacial hydrology (Mathews, 1964, 1973; Meier, 1965; Stenborg, 1969 ,

\footnotetext{
* Now at Department of Geophysics, Stanford University.
} 
1973; Hodge, 1976, 1979; Engelhardt, 1978; Engelhardt and others, 1978; Iken and others, 1979; Röthlisberger and others, 1979). Water-level soundings in bore holes drilled to glacier beds clearly indicate the existence of channels in which the water pressure may be substantially less than the overburden pressure. Fluctuations in bore-hole water levels have been attributed to variations in both melt-water input and the geometry of the subglacial drainage system. Furthermore, the probability of bore holes connecting to subglacial water channels may vary widely from year to year at any point on a glacier. These studies have also provided estimates of the amount of water stored within glaciers and the speed at which water moves through the ice.

Studies of recently deglaciated rock surfaces have also provided important data on the geometry of subglacial drainage networks. Walder and Hallet (1979) and Hallet and Anderson (in press) mapped systems of interconnecting channels and cavities comprising about $20-40 \%$ of the former beds of two small cirque glaciers. Variation in the subglacial hydraulic network through time was clearly indicated by the fact that many channels incised into the rock by turbulent subglacial melt water were also coated with $\mathrm{CaCO}_{3}$ precipitate that forms only where the rock is in intimate contact with sliding ice (Hallet, 1979). The mapping by Walder and Hallet (1979) further revealed 5-10 m wide zones, paralleling the former direction of ice flow, which were thoroughly striated and nearly devoid of the precipitate. Apparently, the bed in these zones had been covered by a water sheet accommodating a water flux sufficient to inhibit the build-up of the solute concentration to the saturation point. Hallet (1979) has estimated from the size distribution of rock fragments in the subglacial precipitate, that over most of the bed of the glacier studied, the water sheet was typically no thicker than several tens of micrometers, possibly thickening at times to $c .100 \mu \mathrm{m}$.

The picture of the subglacial drainage system arising from these various studies is similar to that envisioned by Nye (1973): a thin water sheet over most of the bed, co-existing with but relatively independent of discrete channels that drain most of the melt water. Furthermore, both channelized and sheet flow are variable in time and space. Theoretical models should account for these observations. Significant progress toward the development of such models has been made by Röthlisberger (1972) and Shreve (1972), who showed independently that channelized flow tends to become concentrated, with larger channels growing at the expense of smaller ones, forming an arborescent network. Both of these authors argued that the stable form of subglacial water passages should be tunnel-like rather than sheet-like. However, Weertman (1972) showed that discrete channels at the glacier bed might not be efficient melt-water collectors, due to the effective linearization of the creep law for ice in the particular case of tunnel closure when the relatively high shear stress at the bed is explicitly considered. Weertman showed that this linearization of the creep law could result in pressure gradients that would actually drive water away from channels at the glacier bed. He therefore concluded that primary drainage of melt water at the beds of temperate glaciers must be through a widespread, relatively thick sheet of water. Nye's (1976) study of a jökulhlaup, however, has led him to conclude otherwise. Although Nye did not explicitly determine the temperature distribution, and hence the heat flow, in a sheet of water at the bed of a temperate glacier, he argued that heterogeneous heat production in a water sheet of variable thickness should lead to flow localization. Nye's argument serves as a starting point for the analysis presented here.

In this paper, I have analyzed in detail the stability of sheet flow of water at the bed of a temperate glacier with respect to perturbations in the sheet thickness. I also discuss the implications of the results for the well-known water-lubrication theory of glacier surges (Weertman, 1962, 1964, 1966, 1969). 


\section{OUtLINE OF THE ANALYSIS}

Sheet flow of water beneath a temperate glacier tends to be unstable with respect to variations in the sheet thickness, i.e. such variations tend to become enhanced. Physically this effect arises from the greater viscous heat dissipation due to water flow, and concomitant higher melting rate, where the sheet is thickest, as compared to where it is thinnest. In idealized sheet flow, two processes tend to counteract the instability: cross-stream heat flow within the sheet and "plastic" sagging of the ice. Furthermore, incipient channels may be destroyed as the glacier slides over protuberances on its bed (Nye, 1973). The central issue to be addressed is therefore the rate of growth of perturbations in the water sheet.

In section 3, I present solutions for the fluid flow and heat transfer within a subglacial water sheet that varies slightly in thickness along a direction normal to the flow. The analysis is rigorous to first order in the small thickness perturbation. Adoption of the sheet-flow approximation is tantamount to assuming that the glacier bed is smooth on a scale large compared with the sheet thickness. Formal incorporation of the effects of glacier bed irregularities and subglacial drift would greatly complicate the model, but would be unlikely to alter our picture of the fundamental physics involved.

Sagging of the ice is analyzed in section 4 by considering the ice-water contact to be the interface between two linear viscous fluids and studying the relaxation behaviour of perturbations on an otherwise planar interface, following the method of Fletcher (1977). In section 5, I discuss how the roughness of real glacier beds may be incorporated into the model in an approximate fashion, as well as the implications of my results for Weertman's (1962, 1964, 1966, 1969) water-lubrication theory of glacier surges.

\section{Fluid FLOW AND heAt TRANSFER IN THE WATER SHEET}

In this section, I derive expressions for the flow velocity and temperature distribution in a subglacial water sheet of variable thickness. Several simplifying assumptions are made about the geometry. Water flow is assumed to be steady, one-dimensional, and parallel to the ice flow. The bed is considered to be essentially planar, with the surface slope $\alpha$ of the ice providing a constant pressure gradient driving the flow. The water pressure is assumed to be equal to the ice overburden pressure $p$. In reality, sliding of the ice over bedrock protuberances will result in regions of high pressure where the water sheet is largely squeezed out. Water will then tend to flow around these regions, resulting in a slightly lower average pressure gradient in the sheet (Weertman, 1972, p. 311-12), as well as two-dimensional flow. Again, this effect is unlikely to alter the results of the simple model fundamentally.

The coordinate system and idealized water-sheet geometry are depicted in Figure 1, with $x$ representing distance along the bed in the flow direction, $y$ perpendicular to $x$ and along the bed (the "lateral" direction), and $z$ perpendicular to the bed. The glacier bed, assumed impermeable, is at $z=0$. The water-ice interface is described by the expression

$$
z=z_{0}(y)=h(1+\varepsilon \sin k y)
$$

where $h$ is the average thickness of the sheet and $\varepsilon \ll 1$. The amplitude $A$ of the perturbation 


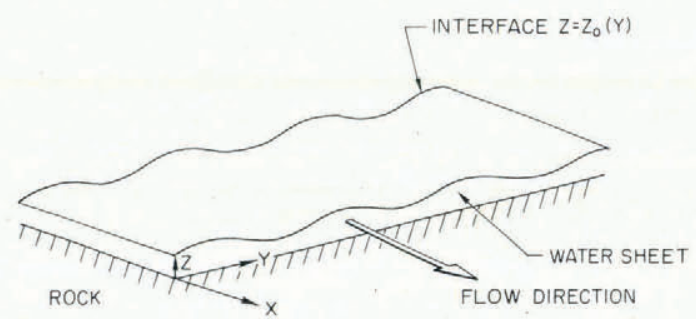

Fig. 1. Coordinate system and idealized water-sheet geometry for the theoretical analysis.

therefore equals $\varepsilon h$. The Navier-Stokes equations for steady flow reduce to (Bird and others, [ $\left.{ }^{\mathrm{c}} 1960\right]$, p. 80)

$$
\frac{\partial^{2} u}{\partial y^{2}}+\frac{\partial^{2} u}{\partial z^{2}}=-\frac{P_{g}}{\eta_{w}}
$$

where $u$ is the flow velocity, $P_{\mathrm{g}}=-\partial p / \partial x$ is the pressure gradient driving the flow, the sign chosen as to make $P_{\mathrm{g}}>0$, and $\eta_{\mathrm{w}}$ is the viscosity of water.

I now assume that the flow velocity can be expressed as a mean flow plus a small perturbation:

$$
u(y, z)=u_{0}(z)+\varepsilon u_{1}(y, z) .
$$

Substituting Equation (3) into Equation (2) and separating terms of $O(1)$ and $O(\varepsilon)$ leads to the two differential equations

$$
\begin{gathered}
\frac{\mathrm{d}^{2} u_{0}}{\mathrm{~d} z^{2}}=-\frac{P_{\mathrm{g}}}{\eta_{\mathrm{w}}}, \\
\frac{\partial^{2} u_{1}}{\partial y^{2}}+\frac{\partial^{2} u_{1}}{\partial z^{2}}=0 .
\end{gathered}
$$

The boundary conditions on the flow are

$$
u=0 \quad \text { on } z=0, z=z_{0}(y) .
$$

These are to be satisfied to $O(\varepsilon)$. The following velocity distribution in the sheet, which satisfies these boundary conditions, is derived in Appendix B:

$$
u(y, z)=\frac{P_{\mathrm{g}} h^{2}}{2 \eta_{\mathrm{w}}}\left[-\frac{z^{2}}{h^{2}}+\frac{z}{h}+\varepsilon \frac{\sinh k z \sin k y}{\sinh k h}\right] .
$$

This expression is used in computing the temperature field in the water sheet. The thermal energy equation for steady-state, incompressible, one-dimensional flow is (Bird and others, [ $\left.{ }^{\mathrm{c}} 1960\right]$, p. 315)

$$
\rho_{\mathrm{w}} c_{\mathrm{w}} u \frac{\partial T}{\partial x}=k_{\mathrm{w}} \nabla^{2} T+\eta_{\mathrm{w}}\left[\left(\frac{\partial u}{\partial y}\right)^{2}+\left(\frac{\partial u}{\partial z}\right)^{2}\right]
$$

where $T$ is the water temperature; $\nabla^{2}$ is the three-dimensional Laplacian operator in Cartesian 
coordinates, $\rho_{\mathrm{w}}, c_{\mathrm{w}}$, and $k_{\mathrm{w}}$ are the density, constant-volume specific heat, and thermal conductivity, respectively, for water at the melting point.

In Appendix $\mathrm{C}$, it is shown by dimensional analysis that both down-stream and lateral heat conduction, corresponding respectively to the terms $k_{\mathrm{w}} \partial^{2} T / \partial x^{2}$ and $k_{\mathrm{w}} \partial^{2} T / \partial y^{2}$, are negligible in the overall heat balance in nearly all instances, including the interesting case of a sheet thick enough substantially to affect bed roughness. However, the small, but finite, amount of lateral heat conduction might be expected to affect the growth rate of perturbations; hence the term $k_{\mathrm{w}} \partial^{2} T / \partial y^{2}$ will be retained in the thermal energy balance.

One further simplification is made to permit an analytic solution to Equation (6). The temperature of the water in a thin sheet is expected to differ only very slightly from the pressuremelting temperature, hence the approximations

$$
\left.\begin{array}{l}
T \approx T_{\mathrm{m}}, \\
\frac{\partial T}{\partial x} \approx c_{\mathrm{t}} P_{\mathrm{g}}
\end{array}\right\}
$$

where $T_{\mathrm{m}}$ is the pressure-melting temperature and $c_{\mathrm{t}}=-\partial T_{\mathrm{m}} / \partial p$, the choice of sign making $c_{\mathrm{t}}>0$. Since a constant pressure gradient has been assumed, $\partial T / \partial x$ is constant in this approximation. Substituting Equations (8) into Equation (7) and neglecting down-stream conduction, the thermal energy equation reduces to

$$
\gamma P_{\mathrm{g}} u=k_{\mathrm{w}}\left(\frac{\partial^{2} T}{\partial y^{2}}+\frac{\partial^{2} T}{\partial z^{2}}\right)+\eta_{\mathrm{w}}\left[\left(\frac{\partial u}{\partial y}\right)^{2}+\left(\frac{\partial u}{\partial z}\right)^{2}\right]
$$

where $\gamma=\rho_{\mathrm{w}} c_{\mathrm{w}} c_{\mathrm{t}}=0.316$ is a dimensionless constant that arises from the pressure-melting behaviour of ice (Röthlisberger, 1972).

The temperature field is now decomposed into a mean and a small perturbation:

$$
T(x, y, z)=T_{0}(x, z)+\varepsilon T_{1}(y, z) .
$$

The boundary conditions on the temperature field are

$$
\left.\begin{array}{l}
T\left(z=z_{0}\right)=T_{\mathrm{m}}(x)=-c_{\mathrm{t}} p(x) \\
-k_{\mathrm{w}} \frac{\partial T}{\partial z}(z=0)=q_{\mathrm{G}},
\end{array}\right\}
$$

where $q_{\mathrm{G}}$ is the geothermal heat flux at the bed. Equation (9) can be transformed into two equations to be solved independently for $T_{0}$ and $T_{1}$, subject to the boundary conditions of Equations (11). Details of the rather lengthy analysis are given in Appendix D. The quantity of greatest interest for the stability analysis is the heat flux from the water sheet into the basal ice, $-k \partial T / \partial n$ where $n$ is the local upward normal from the ice-water interface. Applying the chain rule for differentiation and noting from Equation (1) that the slope $\partial z_{0} / \partial y$ of the interface is $O(\varepsilon)$, it follows that, to $O(\varepsilon)$,

$$
\frac{\partial T}{\partial n}=\frac{\partial T}{\partial z}
$$


The heat flux into the basal ice, denoted $Q_{Z_{0}}$, is given by Appendix D:

$$
\begin{aligned}
Q_{z_{0}}=\left\{q_{\mathrm{G}}+\frac{P_{\mathrm{g}}^{2} h^{3}(1-\gamma)}{12 \eta_{\mathrm{w}}}\right\}+\left\{\frac{P_{\mathrm{g}}^{2} h^{3}(1-\gamma)}{4 \eta_{\mathrm{w}}} \varepsilon\right. & \sin k y\}- \\
& -\left\{\left[\frac{P_{\mathrm{g}}^{2} h^{3}(1-\gamma)}{6 \eta_{\mathrm{w}}}+q_{\mathrm{G}}\right] k^{2} h^{2} \varepsilon \sin k y\right\}
\end{aligned}
$$

where I have introduced the approximation $k h \ll 1$, i.e. the wavelength $(=2 \pi / k)$ of the perturbation is large compared with the sheet thickness. For such values of $k h$, the functional form of the heat flux is most readily understood.

In Equation (13), the heat flux has been separated into three bracketed members. The first is the mean heat flux, composed of terms representing geothermal heat and viscous dissipation. The factor $(1-y) \approx \frac{2}{3}$ corrects for the net down-stream advection of heat that maintains the water at the pressure-melting temperature.

The second bracketed member of Equation (13) is the locally enhanced viscous heat production in the water sheet, again corrected for down-stream advection. Heat flow into the ice, and therefore melting, is greater in the thick parts of the sheet $(\sin k y>0)$ than in the thin parts $(\sin k y<0)$. This is now clearly seen to be the source of instability.

Finally, the third member of Equation (13) accounts for heat conducted laterally from thick to thin parts of the sheet, as a result of the warping of the isotherms in the sheet, relative to the unperturbed case. This quantity is seen to be $O\left(k^{2} h^{2}\right)$ and thus of negligible importance for $k h \ll 1$, in agreement with the scaling arguments of Appendix B.

The rate at which perturbations grow due to melting can now be examined. The melting rate of the basal ice is $Q_{z_{0}} / \rho_{\mathrm{i}} L$, where $\rho_{\mathrm{i}}$ is the density of ice and $L$ is the heat of fusion. Neglecting the mean heat flux, which causes equal amounts of melting everywhere on the ice-water interface and does not affect perturbations, the speed $w_{\mathrm{m}}$ at which the interface moves due to melting is found to be

$$
w_{\mathrm{m}}=\left\{\frac{P_{\mathrm{g}}^{2} h^{3}(1-\gamma)}{4 \eta_{\mathrm{w}} \rho_{\mathrm{i}} L}-\left[\frac{P_{\mathrm{g}}^{2} h^{3}(1-\gamma)}{6 \eta_{\mathrm{w}} \rho_{\mathrm{i}} L}+\frac{q_{\mathrm{G}}}{\rho_{\mathrm{i}} L}\right] k^{2} h^{2}\right\} \varepsilon \sin k y
$$

in the next section, the speed at which the ice-water interface moves due to sagging of the ice is determined. The sum of that speed and $w_{\mathrm{m}}$ will then determine the growth rate of perturbations.

\section{SAgging OF THE ICE AND GROWTH RATE OF PERTURbations}

The relaxation of the perturbed ice-water interface can be analyzed by treating the interface as one between two fluids of different densities and viscosities. This approach is widely used in the theory of folding of layered materials; I apply here the particular method developed by Fletcher (1977). In this formulation, the fluids are assumed incompressible and quasi-static, i.e. accelerations are ignored. The rheology is taken as linear viscosity. The choice of rheology is particularly suitable for this model, because for incipient channels at the glacier bed the difference between ice and water pressures will not be large compared to the shear stress, thus effectively linearizing the creep law (Weertman, 1972, p. 299-306). Stresses and velocities are then each decomposed into a mean and a small perturbation. In this particular model, the mean stress is hydrostatic pressure, while the mean velocities are identically zero. Velocity components 
$v$ and $w$ are associated with the relaxation process and correspond to the $y$ - and $z$-directions, respectively. Boundary conditions on stresses and velocities are satisfied to first order in the slope of the perturbed interface, i.e. to $O(k A)$, where $k A \ll 1$ is assumed.

In practice, the effective viscosity of ice is so much larger than that of water, that the analysis reduces to a determination of the speed at which perturbations relax on a free surface. The quantity of interest is $w_{\mathrm{p}}$, the speed at which the interface moves due to viscous sagging. From Appendix E, Equation E-3,

$$
w_{\mathrm{p}}=-\frac{\left(\rho_{\mathrm{w}}-\rho_{\mathrm{i}}\right) g A}{2 \eta_{\mathrm{i}} k} \sin k y
$$

where $g$ is the acceleration due to gravity and $\eta_{\mathrm{i}}$ is the effective viscosity of ice.

The mean rate of melting of the basal ice maintains an average sheet thickness of $h$; heterogeneities in melting and sagging rates cause the amplitude of the thickness perturbation to change quasi-statically, but without any change in the mean thickness of the water sheet. Adopting this view, points on the interface $z=z_{0}$ can be considered as remaining on the interface. Mathematically, this is expressed as (Fletcher, 1977, p. 600)

$$
\frac{\mathrm{D}}{\mathrm{D} t}\left[z-z_{0}(y, t)\right]=0 \quad \text { on } z=z_{0}
$$

where $\mathrm{D} / \mathrm{D} t=(\partial / \partial t)+v(\partial / \partial y)+w(\partial / \partial z)$ is the total time derivative. Expanding Equation (16) yields

$$
\frac{\partial z_{0}}{\partial t}=w_{\mathrm{p}}+w_{\mathrm{m}}-v\left(z_{0}\right) \frac{\partial z_{0}}{\partial y} .
$$

Substituting Equations (1), (14), and (15), recalling that $A=h \varepsilon$, and noting from Appendix E that $v$ is of $O(k A)$, I find to $O(k A)$, after rearranging:

$$
\frac{1}{A} \frac{\mathrm{d} A}{\mathrm{~d} t}=\frac{1}{\tau_{1}}\left(1-\frac{2}{3} k^{2} h^{2}\right)-\frac{1}{\tau_{2}}-\frac{1}{\tau_{3}}\left(k^{2} h^{2}\right)
$$

where

$$
\frac{1}{\tau_{1}}=\frac{P_{\mathrm{g}}^{2} h^{2}(1-\gamma)}{4 \eta_{\mathrm{w}} \rho_{\mathrm{i}} L} ; \quad \frac{1}{\tau_{2}}=\frac{\left(\rho_{\mathrm{w}}-\rho_{\mathrm{i}}\right) g}{2 \eta_{\mathrm{i}} k} ; \quad \frac{1}{\tau_{3}}=\frac{q_{\mathrm{G}}}{\rho_{\mathrm{i}} L h},
$$

and $k h \ll 1$. Table I lists values of $1 / \tau_{1}, 1 / \tau_{2}$, and $1 / \tau_{3}$ for several choices of $P_{\mathrm{g}}, h$, and $k$; the values of the other physical constants are in Appendix A. It is clear that $1 / \tau_{3}$ is negligible in all instances and that $1 / \tau_{2} \ll 1 / \tau_{1}$ unless $h$ and $k$ are very small. Neglecting these cases and noting the restriction $k h \ll 1$, Equation (18) can be closely approximated as

$$
\frac{1}{A} \frac{\mathrm{d} A}{\mathrm{~d} t}=\frac{1}{\tau_{1}} .
$$

The amplitude of small perturbations in the water sheet therefore grows exponentially with time constant $\tau_{1}$. The strength of the instability increases with increasing $P_{\mathrm{g}}$ and $h$. Figure 2 shows $\tau_{1}$ as a function of $h$ for three reasonable choices of $P_{\mathrm{g}}$, the term $k^{2} h^{2}$ being neglected. 
TABle I. TIME CONSTANTS DESCRIBING RATE OF GROWTH OF WATER SHEET PERTURBATIONS

\begin{tabular}{llll}
\multicolumn{1}{c}{$P_{\mathrm{g}}\left(\right.$ bar m $\left.^{-1}\right)$} & & \multicolumn{1}{c}{$1 / \tau_{1}$} & \\
$h$ & $10^{-3}$ & $5 \times 10^{-3}$ & $10^{-2}$ \\
$\mathrm{~mm}$ & $a^{-1}$ & $a^{-1}$ & $a^{-1}$ \\
0.1 & $9.1 \times 10^{-4}$ & $2.2 \times 10^{-2}$ & $9.1 \times 10^{-2}$ \\
0.5 & $2.2 \times 10^{-2}$ & $5.6 \times 10^{-1}$ & 2.2 \\
1 & $9.1 \times 10^{-2}$ & 2.2 & 9.1 \\
5 & 2.2 & $5.6 \times 10^{1}$ & $2.2 \times 10^{2}$ \\
10 & 9.1 & $2.2 \times 10^{2}$ & $9.1 \times 10^{2}$ \\
50 & $2.2 \times 10^{2}$ & $5.6 \times 10^{3}$ & $2.2 \times 10^{4}$
\end{tabular}

$\begin{array}{rlcl}\begin{array}{l}k \\ \mathrm{~m}^{-1}\end{array} & 1 / \tau_{2} & \begin{array}{l}h \\ \mathrm{~mm}\end{array} & 1 / \tau_{3} \\ 0.1 & 4.3 \times 10^{-2} & 0.1 & 1.6 \times 10^{-6} \\ 0.5 & 8.8 \times 10^{-3} & 0.5 & 3.3 \times 10^{-7} \\ 1 & 4.3 \times 10^{-3} & 1 & 1.6 \times 10^{-7} \\ 5 & 8.8 \times 10^{-4} & 5 & 3.3 \times 10^{-8} \\ 10 & 4.3 \times 10^{-4} & 10 & 1.6 \times 10^{-8} \\ 50 & 8.8 \times 10^{-5} & 50 & 3.3 \times 10^{-9}\end{array}$

\section{EFFECTS OF BED ROUGHNESS AND IMPLICATIONS FOR GLACIER SURGING}

The analysis above demonstrates that sheet flow on a planar glacier bed would be unstable with respect to perturbations in sheet thickness. The roughness of actual glacier beds will alter this simple result in two ways, however. First, perturbations in the water sheet, also referred to as "incipient channels", may be destroyed as the glacier slides over protuberances on the bed (cf. Nye, 1973). Second, sub-glacial cavities on the lee sides of bed protuberances may capture

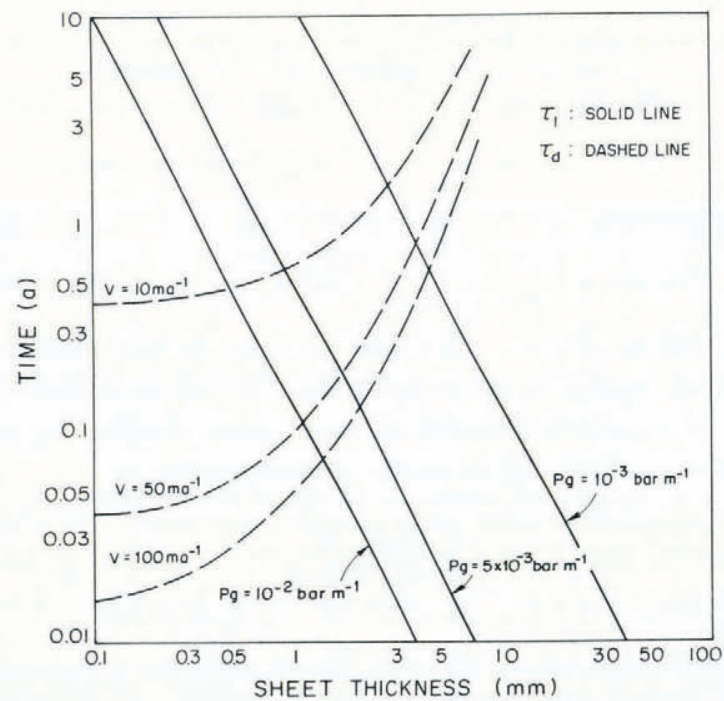

Fig. 2. Characteristic growth and decay times ( $\tau_{1}$ and $\tau_{\mathrm{d}}$ respectively) for water-sheet perturbations. 
significant amounts of melt water and limit the thickness of water sheets (Walder and Hallet, 1979; Hallet and Anderson, in press).

The rate at which incipient channels in the basal ice encounter bed protuberances must generally increase as sliding velocity and bed roughness increase. The criterion for sheet stability used herein is that the sheet will be considered quasi-stable when the average time between encounters with bed protuberances, hereinafter referred to as the "decay time" $\tau_{\mathrm{d}}$, exceeds the characteristic time for growth of sheet perturbations.

A rigorous analysis of the rate at which incipient channels are destroyed by encounters with bed protuberances would involve coupling glacier sliding physics with that of water flow in a "sheet" of complex geometry and spatially variable pressure gradient. Such is beyond the scope of this paper. Nonetheless, a reasonable first approximation to the solution of this problem may be found by adopting a glacier bed model of small hemispheres distributed on a plane. This model was used by Lliboutry (1978) in his formulation of glacier sliding theory. As the glacier slides, incipient channels in the basal ice will encounter these bed irregularities and may be destroyed if the irregularities are neither very small nor very large compared to $R_{\star}$, the "transition obstacle size" in Lliboutry's (1978) glacier sliding theory. Very small irregularities would be submerged by the water sheet, whereas the glacier would slide over large protuberances predominantly by plastic deformation with very little regelation. In the latter case, flow lines in the ice would be very nearly parallel to the bed; hence, the form of the incipient channel could be preserved.

Following Lliboutry (1978, p. 152), I assume a "non-dimensional" bed, such that the fraction of the bed covered by hemispherical bed irregularities with radii in the range $(R, R+\mathrm{d} R)$ is equal to $\mu \mathrm{d} R / R$ where $\mu$, a constant, is a measure of the bed roughness. The fraction of the bed covered by all irregularities is thus $\mu \ln \left(R_{\max } / R_{\min }\right)$, where $R_{\max }$ and $R_{\min }$ are, respectively, the maximum and minimum radii of bed irregularities. This fraction is assumed to be $\ll 1$. Lliboutry suggests $R_{\min }=1 \mu \mathrm{m}, R_{\max }=10 \mathrm{~m}$, hence $\ln \left(R_{\max } / R_{\min }\right) \approx 16$ and $\mu$ must be $\ll \frac{1}{16}$. Due to the logarithmic dependence, $R_{\max }$ and $R_{\min }$ may vary significantly from these suggested values without appreciably affecting the constraint on $\mu$.

As discussed above, bed irregularities with radii near $R_{\star}$ are most "effective" at destroying incipient channels. I will use the following form for the "relative efficiency":

$$
E=\frac{2 R R_{\star}}{R^{2}+R_{\star}^{2}},
$$

which is quite similar to the expression found by Watts (unpublished) for the drag on a sphere moving through temperate ice. The chosen functional form of $E$ has the properties that $E\left(R_{\star}\right)=1$, and that $E$ approaches zero as $R$ approaches zero or infinity.

The number of bed irregularities per unit area of the bed, with radii in the range $(R, R+\mathrm{d} R)$, is (Lliboutry, 1978, p. 152)

$$
\mathrm{d} \nu=\frac{\mu \mathrm{d} R}{\pi R^{3}},
$$

hence, the "effective" number $\nu_{\mathrm{e}}$ of bed irregularities per unit bed area, i.e. the number that may actually destroy an incipient channel, is

$$
\nu_{\mathrm{e}}=\frac{2 \mu R_{\star}}{\pi} \int_{W / 2}^{\infty} \frac{\mathrm{d} R}{R^{2}\left(R^{2}+R_{\star}^{2}\right)}
$$


where the lower limit of integration reflects the size of the smallest bed irregularities that "block" an incipient channel of width $W$.

The average number of the "effective" irregularities along the flow direction in a rectangular bed area of length $l$ along the flow direction, width $W$, is $\nu_{\mathrm{e}} l W$. Because the average spacing of these irregularities is $l / \nu_{\mathrm{e}} l W$, the average time between encounters with such irregularities can be expressed as

$$
\tau_{\mathrm{d}}=\frac{\pi R_{\star}}{2 \mu U W}\left\{\frac{2}{W}+\frac{1}{R_{\star}}\left[\tan ^{-1}\left(\frac{W}{2 R_{\star}}\right)-\frac{\pi}{2}\right]\right\}^{-1}
$$

where I have evaluated the integral in Equation (22). Lliboutry (1978, p. 152) suggested that $R_{\star}=0.16 U^{-1 / 2}$, for $R_{\star}$ in meters, $U$ in meters per year. Although the coefficient of 0.16 is probably incorrect, due to the fact that Lliboutry's (1978) glacier sliding model does not fully satisfy thermal boundary conditions at the glacier bed (recognized by Lliboutry $(1979$, p. 80)), increasing or decreasing this coefficient by a factor of two can be shown not to affect the results presented herein substantially. Hence, using Lliboutry's expression, Equation (23) becomes

$$
\tau_{\mathrm{d}}=\left(\frac{0.08 \pi}{\mu W U^{3 / 2}}\right)\left\{\frac{2}{W}+6.25 U^{1 / 2}\left[\tan ^{-1}\left(3.12 W U^{1 / 2}\right)-\frac{\pi}{2}\right]\right\}^{-1} .
$$

The width $W$ of an incipient channel can be identified with the wavenumber $k$ of the water sheet perturbation by the relationship $W=\pi k^{-1}$; i.e. $W$ is the perturbation half-wavelength. The analysis for the growth of perturbations is valid for $k h \ll 1$; hence, the width of incipient channels that can be examined by the present analysis is constrained by the relationship $W \gg \pi h$. A reasonable minimum value for $W$ is therefore $30 h$. Using this value, I can rewrite Equation (24) as

$$
\tau_{\mathrm{d}}=\left(\frac{0.84}{h U^{3 / 2}}\right)\left\{\frac{0.067}{h}+6.25 U^{1 / 2}\left[\tan ^{-1}\left(93.75 h U^{1 / 2}\right)-\frac{\pi}{2}\right]\right\}^{-1}
$$

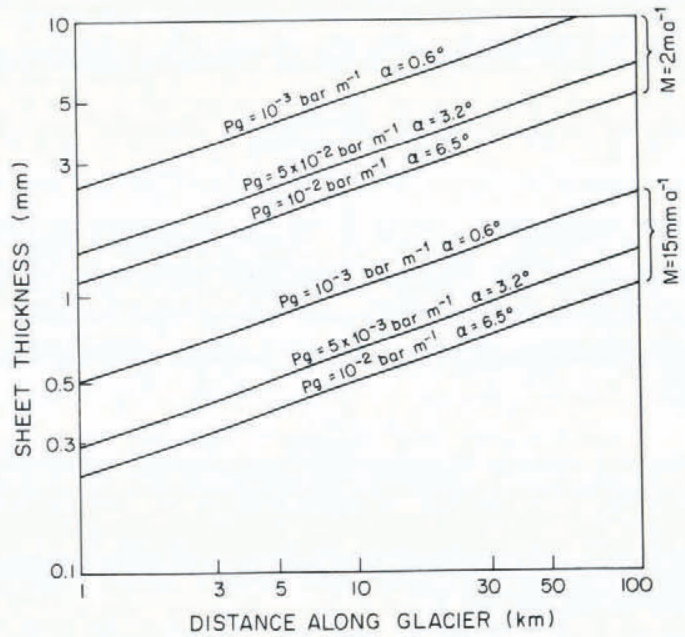

Fig. 3. Thickness of water sheet as a function of distance along the ice-flow direction, assuming all melt water flows in the sheet. 
where $h$ is expressed in meters, $U$ in meters per year, $\tau_{\mathrm{d}}$ in years, and $\mu=0.01$ in accord with the constraint discussed above. This relationship has been plotted in Figure 2 for three choices of $U$. The values of $\tau_{\mathrm{d}}$ computed from Equation (25) are minimum values, because $\tau_{\mathrm{d}}$ increases with $W$. The criterion for water-sheet stability used here is that $\tau_{\mathrm{d}}\left\langle\tau_{1}\right.$ for the specified values of $P_{\mathrm{g}}$ and $U$; hence, by using Equation (25) for $\tau_{\mathrm{d}}$, the probability of sheet stability is maximized.

It appears from Figure 2 that, for reasonable choices of $P_{\mathrm{g}}$ and $U$, the stability criterion can be met only for $h<c .1-4 \mathrm{~mm}$. Sheets of greater thickness will tend to be unstable. Weertman $(1962,1964,1966,1969)$ argued that a water sheet thick enough substantially to reduce effective bed roughness will cause an increase in sliding velocity of one to two orders of magnitude, i.e. a glacier surge. He approximated bed roughness by cubes, with those of side $\Lambda$ being most important in causing drag on the sliding ice. The homologous quantity in Lliboutry's (1978) theory is $R_{\star}$, which can be expressed in terms of $U$. If a sheet of thickness $h \geqslant R_{\star}$ is stable to thickness perturbations, then Weertman's mechanism might operate.

Table II gives values of $h_{\max } / R_{\star}$, where $h_{\max }$ is the maximum stable thickness, for several choices of $P_{\mathrm{g}}$ and $U$. In all cases examined, encompassing the great majority of actual glaciers, $h_{\max } / R_{\star}$ is much less than unity; the largest values of $h_{\max } / R_{\star}$ are found when $P_{\mathrm{g}}$ is relatively small and $U$ relatively large, i.e. for gently sloping, fast-moving glaciers. Hence, the conclusion reached from the present model is that the Weertman water-lubrication mechanism is unlikely to be effective for surge initiation. However, this mechanism may be effective at maintaining surges once high sliding velocities are achieved. Caution must be taken with this conclusion, however. If bed irregularities of width $R<\frac{1}{2} W$ can cause destruction of incipient channels, then $\tau_{\mathrm{d}}$ could be reduced considerably from that given by Equation (25) with the result that thicker sheets could be stable.

An independent and fundamentally important consideration in evaluating the waterlubrication theory of surges is whether sufficient melt water is ever available at the bed to cause thick water sheets. The thickness of such a sheet at the glacier bed may be computed by assuming that uniform melting of thickness $M$ per unit time occurs everywhere on the base of the glacier, and that all melt water flows at the bed. The sheet thickness is then (Weertman, 1969, p. 953)

$$
h=\left(\frac{12 M x}{P_{\mathrm{g}}}\right)^{1 / 3}
$$

where $x=0$ is the point farthest from the glacier terminus. Figure 3 shows $h$ as a function of $x$ for several values of $M$ and $P_{\mathrm{g}}$, the latter also expressed as surface slope $\alpha$. For typical values of geothermal heat flux $\left(c .0 .05 \mathrm{~J} \mathrm{~m}^{-2} \mathrm{~s}^{-1}\right)$, a bed shear stress of $c .1$ bar, and sliding velocity $U$ up to several tens of $\mathrm{m} \mathrm{a}^{-1}, M=c .15 \mathrm{~mm} \mathrm{a}^{-1}$. Figure 3 shows that with such a melting rate, $h \leqslant 2 \mathrm{~mm}$ for glaciers less than $c .100 \mathrm{~km}$ long, regardless of surface slope. Such a value of $h$ is

TABLE II. RATIO OF THE MAXIMUM STABLE SHEET THICKNESS $h_{\max }$ TO THE TRANSITION OBSTACLES SIZE $R_{\star}$

\begin{tabular}{|c|c|c|c|}
\hline$P_{\mathrm{g}}\left(\right.$ bar m $\left.^{-1}\right)$ & \multicolumn{2}{|c|}{$h_{\max } / R \star$} & \\
\hline $\mathrm{mm} \mathrm{a}^{-1}$ & $10^{-3}$ & $5 \times 10^{-3}$ & $10^{-2}$ \\
\hline 10 & 0.06 & 0.02 & 0.01 \\
\hline 50 & 0.17 & 0.08 & 0.05 \\
\hline 100 & 0.27 & 0.12 & 0.08 \\
\hline
\end{tabular}


less than estimates of the height of the most important bed-roughness elements. Thus, "normal" melting rates are very unlikely to produce water sheets thick enough to substantially reduce bed roughness.

In order for $h$ to reach even $5 \mathrm{~mm}$, a likely lower limit for the "controlling obstacle size", $M$ must be considerably larger than $15 \mathrm{~mm} \mathrm{a}^{-1}$. Studies of intergranular vein structures in temperate glacier ice (Raymond and Harrison, 1975), and of ice chemistry (Berner and others, 1978), suggest that as much as $c .100 \mathrm{~mm} \mathrm{a}^{-1}$ of melt water can percolate to the glacier bed through intergranular veins. However, even for an effective melting rate of $M=120 \mathrm{~mm} \mathrm{a}^{-1}$, an eight-fold increase from the "normal" melting rate, $h$ will be increased by a factor of only two and will therefore still be less than $5 \mathrm{~mm}$ for glaciers of lengths less than c. $100 \mathrm{~km}$.

It appears that other distributed sources of large amounts of melt water are necessary if the subglacial water sheet is to become thick enough to initiate surges. As shown in Figure 3, an effective melting rate of $2 \mathrm{~m} \mathrm{a}^{-1}$ could produce a sheet of thickness $c .5 \mathrm{~mm}$ for glaciers with lengths $c$. 10-50 km and surface slopes of $c$. 0.5-4.0. A number of surging glaciers have these dimensions (Meier and Post, 1969). It is clear that water flows through englacial and subglacial conduits, as well as through intergranular veins (Mathews, 1964; Röthlisberger, 1972; Shreve, 1972; Weertman, 1972; Nye, 1973, 1976; Vivian and Zumstein, 1973; Hodge, 1974, 1976, 1979; Raymond and Harrison, 1975; Engelhardt, 1978; Engelhardt and others, 1978; Röthlisberger and others, 1979; Walder and Hallet, 1979), but estimates of the magnitude of such flows are not available. Furthermore, it is possible that melt water reaching the bed through such conduits would remain channelized, rather than spreading out (Shreve, 1972). The fact that bore holes drilled to glacier beds often encounter channels suggests that such melt water does not join a subglacial water sheet. Considerably more information is needed about the hydrology of temperate glaciers before it can be established that major distributed water sources can actually supply a subglacial water sheet.

A final consideration, related to the above discussion of melt water supply, is the amount of water flow through subglacial cavities. Walder and Hallet (1979) and Hallet and Anderson (in press) have shown that cavities may comprise as much as $20-40 \%$ of the ice-rock interface beneath two small cirque glaciers. Hallet and Anderson have calculated that the potential water storage in an exhumed cavity network at Castleguard Glacier, Alberta, would be equivalent to a sheet of water $63 \mathrm{~mm}$ thick, if all cavities were filled. Hodge (1974) estimated that the water stored at the beds of Nisqually Glacier and South Cascade Glacier, later released during jökulhlaups, could amount to an equivalent water layer approximately $1 \mathrm{~m}$ thick. Furthermore, because the subglacial cavities are regions of relatively low water pressure, they tend to act as continual "sinks" for subglacial melt water. The total of the water stored in subglacial cavities, plus the through-flow of water in the cavity-channel network (Walder and Hallet, 1979), could amount to a significant fraction of the total annual melt-water production. The water sheet thickness shown in Figure 3 must therefore be considered an upper limit, applicable only in the absence of numerous subglacial cavities. Hence, the presence of water-filled subglacial cavities reduces the possibility that the water lubrication mechanism for glacier surges can operate.

\section{Conclusions}

I have presented a model for the stability of sheet flow of water at the base of a temperate glacier, with respect to perturbations in sheet thickness. Sheet flow is nearly always unstable on planar glacier beds, but the roughness of real beds may result in quasi-stable sheet flow for sheets 
of thickness no greater than c. $4 \mathrm{~mm}$. However, the choice of model for bed roughness has a strong influence on the values determined for maximum stable sheet thickness.

Quasi-stable subglacial water sheets are apparently not thick enough to cause drastic reductions in bed roughness and thereby initiate surges, but may cause some increase in sliding velocity or maintain surges once started.

Regardless of the model chosen for bed roughness, the necessary conditions for a thick water sheet at temperate glacier beds are:

(i) Water-filled subglacial cavities must be rare.

(ii) Large quantities of surface melt water must penetrate to the glacier bed.

\section{AcKNowledgements}

I am grateful to Bernard Hallet for guidance and encouragement through the course of this work, as well as for a critical review of the manuscript. Helpful comments on the theoretical analysis were also made by Raymond Fletcher and Paul Delaney.

This work represents part of a Master's thesis in the Department of Geology, Stanford University.

Financial support was provided by National Science Foundation Grant EAR77-13631 and by the Shell Companies Foundation.

MS. received 23 March 1981 and in revised form 12 June 1981

\section{Appendix A. Symbols and values of constants}

$a_{\mathrm{n}}, b_{\mathrm{n}}, c_{\mathrm{n}}, d_{\mathrm{n}}$
$A$
$A^{\prime}, B^{\prime}, C^{\prime}, D^{\prime}$
$\tilde{A}, \tilde{B}$
$c_{\mathrm{t}}$
$c_{\mathrm{w}}$
$C_{0}(x), C_{1}(x)$
$E(R)$
$f_{0}, g_{0}$
$F(z), G(z)$
$g$
$h$
$h_{\max }$
$k$
$l$
$L$
$M$
$n$
$p$
$P_{\mathrm{g}}$
$(P r)$
$q_{\mathrm{G}}$
$Q_{z_{0}}$
$R$
$R \star$
$(R e)$
$t$

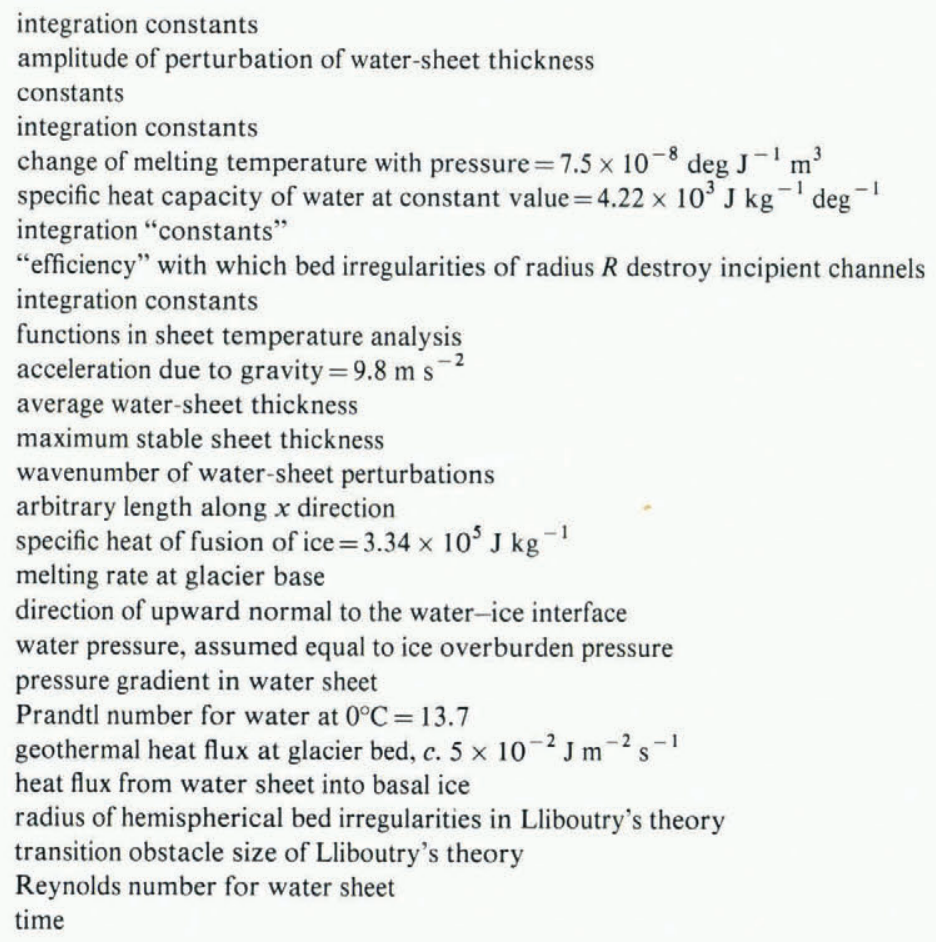




$T$
$T^{\prime}$
$T_{\mathrm{m}}$
$T_{0}$
$T_{1}$
$u, v, w$
$u^{\prime}, v^{\prime}, w^{\prime}$
$u_{0}$
$u_{1}$
$U$
$\tilde{U}, \tilde{W}$
$v_{\mathrm{f}}, w_{\mathrm{f}}$
$W$
$w_{\mathrm{m}}$
$v_{\mathrm{p}}, w_{\mathrm{p}}$
$x, y, z$
$x^{\prime}, y^{\prime}, z^{\prime}$
$z_{0}(y)$
$\alpha$
$\varepsilon$
$\eta_{\mathrm{f}}$
$\eta_{\mathrm{i}}$
$\eta_{\mathrm{w}}$
$\lambda$
$\Lambda$
$\tau_{3}$
$\tau_{\mathrm{v}}$
$\tau_{\mathrm{g}}$
$\tau_{\mathrm{e}}$
$\rho_{\mathrm{i}}$
$\rho_{\mathrm{w}}$
$\tilde{\sigma}_{y z}, \tilde{\sigma}_{z z}$

$\tau_{\mathrm{d}}$

water temperature

dimensionless water temperature

pressure melting temperature

mean water temperature

water temperature perturbation

velocity of water flow in $x, y, z$ directions, respectively

dimensionless water velocities

mean water velocity

water velocity perturbation

glacier sliding velocity

characteristic water velocities

fluid relaxation velocities

width of incipient channels

speed at which ice-water interface moves due to melting

speed at which ice-water interface moves due to sagging

Cartesian coordinates

dimensionless Cartesian coordinates

position of ice-water interface

ice surface slope

dimensionless perturbation parameter, assumed much less than unity

fluid viscosity, used in Appendix E

apparent Newtonian viscosity of ice $=3.2 \times 10^{12} \mathrm{~kg} \mathrm{~m}^{-1} \mathrm{~s}^{-1}$

viscosity of water at $0^{\circ} \mathrm{C}=2 \times 10^{-3} \mathrm{~kg} \mathrm{~m}^{-1} \mathrm{~s}^{-1}$

characteristic length in $y$ direction

controlling obstacle size of Weertman's sliding theory

dimensionless roughness parameter

number of irregularities on glacier bed per unit area

number of irregularities on glacier bed per unit area that are effective at destroying water-sheet perturbations

density of ice $=917 \mathrm{~kg} \mathrm{~m}^{-3}$

density of water at $0^{\circ} \mathrm{C}=999.84 \mathrm{~kg} \mathrm{~m}^{-3}$

stress perturbations

characteristic "decay time" of incipient channels

time constants for growth of perturbations by melting

time constant for decay of perturbations by sagging

time constant describing effect of geothermal heat flux on perturbations

viscous dissipation function

\section{Appendix B. Fluid Flow in the PERTURBed WATER SHEet}

Steady, incompressible flow in the water sheet is described by the equations

$$
\begin{gathered}
\rho_{w}\left(u \frac{\partial u}{\partial x}+w \frac{\partial u}{\partial z}\right)=P_{g}+\eta_{w} \nabla^{2} u, \\
\frac{\partial u}{\partial x}+\frac{\partial w}{\partial z}=0,
\end{gathered}
$$

where $v=0$ has been assumed as has a constant pressure gradient. The velocity $w$ is very small compared with $u$, but not exactly zero, unless the sheet thickness is constant.

Equations (B-1) and (B-2) can be put in the dimensionless forms

$$
\rho_{\mathrm{w}}\left(\frac{\tilde{U}^{2}}{l} u^{\prime} \frac{\partial u^{\prime}}{\partial x^{\prime}}+\frac{\tilde{U} \tilde{W}}{h} w^{\prime} \frac{\partial u^{\prime}}{\partial z^{\prime}}\right)=P_{\mathrm{g}}+\eta_{\mathrm{w}} \tilde{U}\left(\frac{1}{l^{2}} \frac{\partial^{2} u^{\prime}}{\partial x^{\prime 2}}+\frac{1}{\lambda^{2}} \frac{\partial^{2} u^{\prime}}{\partial y^{\prime 2}}+\frac{1}{h^{2}} \frac{\partial^{2} u^{\prime}}{\partial z^{\prime 2}}\right),
$$




$$
\frac{\tilde{U}}{l} \frac{\partial u^{\prime}}{\partial x^{\prime}}+\frac{\tilde{W}}{h} \frac{\partial w^{\prime}}{\partial z^{\prime}}=0
$$

where $\tilde{U}$ and $\tilde{W}$ are characteristic velocities, $l$ is a characteristic length scale in the $x$ direction, $x^{\prime}$ and $z^{\prime}$ are dimensionless Cartesian coordinates, $u^{\prime}$ and $w^{\prime}$ are dimensionless velocities, and other symbols are defined in Appendix A and correspond to usage in the text. Since the dimensionless functions and their derivatives are of $O(1)$, Equation (B-4) demonstrates that $\tilde{W} \approx \tilde{U} h / l$. Using this estimate of $\tilde{W}$, Equation (B-3) can be rewritten as

$$
u^{\prime} \frac{\partial u^{\prime}}{\partial x^{\prime}}+w^{\prime} \frac{\partial u^{\prime}}{\partial z^{\prime}}=\frac{P_{g} l}{\rho \tilde{U}^{2}}+\frac{1}{(R e)}\left[\left(\frac{h}{l}\right) \frac{\partial^{2} u^{\prime}}{\partial x^{\prime 2}}+\left(\frac{l}{h}\right)\left(\frac{h}{\lambda}\right)^{2} \frac{\partial^{2} u^{\prime}}{\partial y^{\prime 2}}+\left(\frac{l}{h}\right) \frac{\partial^{2} u^{\prime}}{\partial z^{\prime 2}}\right],
$$

where $(R e)=\rho_{\mathrm{w}} \tilde{U} h / \eta_{\mathrm{w}}$ is the Reynolds number for true sheet flow; this is expected to differ very little from $(R e)$ for a slightly perturbed sheet. In Equation (B-5), the left side represents inertial effects, while the term in brackets on the right side represents viscous effects. It is shown in Appendix $\mathrm{C}$ that $(R e) \leqslant c .10^{3}$ for nearly all cases of interest; hence, viscous effects dominate inertial effects if the terms in brackets in Equation (B-5) have a value exceeding $c$. $10^{4}$. This condition is satisfied if $l / h>c .10^{4}$. For $h<c .10 \mathrm{~mm}$, this requires $l>c .0 .1 \mathrm{~km}$, a restriction that is virtually always met, since $l$ may be taken as the glacier's length. Hence, it is justifiable to neglect inertial terms in the equation of motion, which reduces, in dimensional form, to

$$
\frac{\partial^{2} u}{\partial y^{2}}+\frac{\partial^{2} u}{\partial z^{2}}=-\frac{P_{8}}{\eta_{w}}
$$

I now assume that $u$ may be expressed as a mean plus a small perturbation, viz.

$$
u(y, z)=u_{0}(z)+\varepsilon u_{1}(y, z)
$$

where $\varepsilon \leqslant 1$. Substituting Equation (B-7) into Equation (B-6) and separating terms of $O(1)$ and $O(\varepsilon)$ leads to the two equations:

$$
\begin{aligned}
& \frac{\mathrm{d}^{2} u_{0}}{\mathrm{~d} z^{2}}=-\frac{P_{\mathrm{B}}}{\eta_{\mathrm{w}}}, \\
& \frac{\partial^{2} u_{1}}{\partial y^{2}}+\frac{\partial^{2} u_{1}}{\partial z^{2}}=0 .
\end{aligned}
$$

Equation (B-8a) can be integrated directly:

$$
u_{0}=-\frac{P_{\mathrm{g}} z^{2}}{2 \eta_{\mathrm{w}}}+\tilde{A} z+\tilde{B}
$$

where $\tilde{A}$ and $\tilde{B}$ are constants. The perturbation $u_{1}$ satisfies the two-dimensional Laplace equation and will have the well-known form,

$$
u_{1}=\sum_{n=1}^{\infty} \sin n k y\left(a_{\mathrm{n}} \sinh n k z+b_{\mathrm{n}} \cosh h k z\right)+\sum_{n=1}^{\infty} \cos n k y\left(c_{\mathrm{n}} \sinh n k z+d_{\mathrm{n}} \cosh n k z\right),
$$

where the $a_{\mathrm{n}}, b_{\mathrm{n}}, c_{\mathrm{n}}$, and $d_{\mathrm{n}}$ are constants to be evaluated.

The boundary conditions to $O(\varepsilon)$ are

$$
u=0 \quad \text { on } z=0, z=h(1+\varepsilon \sin k y) .
$$

The solution for $u$ satisfying these boundary conditions is

$$
u=\frac{P_{g} h^{2}}{2 \eta_{\mathrm{w}}}\left(-\frac{z^{2}}{h^{2}}+\frac{z}{h}+\varepsilon \frac{\sinh k z \sin k y}{\sinh k h}\right) .
$$

Equation (B-12) is used for computing the viscous dissipation $\Phi_{\mathrm{v}}\left(\mathrm{Bird}\right.$ and others, $\left[{ }^{\mathrm{c}} 1960\right]$, p. 316):

$$
\Phi_{\mathrm{v}}=\eta_{\mathrm{w}}\left[\left(\frac{\partial u}{\partial x}\right)^{2}+\left(\frac{\partial u}{\partial y}\right)^{2}+\left(\frac{\partial u}{\partial z}\right)^{2}\right],
$$


where I have assumed one-dimensional, incompressible flow. From the earlier discussion, $\partial u / \partial x$ is assumed to vanish; hence, from Equation (B-12), I can compute

$$
\begin{aligned}
& \frac{\partial u}{\partial y}=\varepsilon \frac{P_{\mathrm{g}} h^{2} k}{2 \eta_{\mathrm{w}}} \frac{\sinh k z \cos k y}{\sinh k h}, \\
& \frac{\partial u}{\partial z}=\frac{P_{\mathrm{g}} h}{2 \eta_{\mathrm{w}}}\left(1-\frac{2 z}{h}\right) .
\end{aligned}
$$

Thus, to $O(\varepsilon)$

$$
\Phi_{\mathrm{v}}=\eta_{\mathrm{w}}\left(\frac{\partial u}{\partial z}\right)^{2}
$$

\section{Appendix C. Dimensional analysis of the thermal energy equation}

A solution to the complete thermal energy equation can rarely be obtained in closed form. Nontheless, appropriate scaling of the equation can elucidate the important physical processes and show which terms may be neglected.

The complete thermal energy equation for one-dimensional, steady, incompressible flow is (Bird and others, [c1960], p. 315)

$$
\rho_{\mathrm{w}} c_{\mathrm{w}} u \frac{\partial T}{\partial x}=k_{\mathrm{w}} \nabla^{2} T+\eta_{\mathrm{w}}\left[\left(\frac{\partial u}{\partial y}\right)^{2}+\left(\frac{\partial u}{\partial z}\right)^{2}\right]
$$

where all symbols are defined in Appendix A. This equation can be put into dimensionless form with the scalings

$$
\begin{aligned}
& x=\left(\frac{\rho_{\mathrm{w}} c_{\mathrm{w}} h^{2} \tilde{U}}{k_{\mathrm{w}}}\right) x^{\prime}, \\
& y=k^{-1} y^{\prime}, \\
& z=h z^{\prime}, \\
& u=\tilde{U} u^{\prime}, \\
& T=\left(\frac{q_{\mathrm{G}} h}{k_{\mathrm{w}}}\right) T^{\prime} .
\end{aligned}
$$

Thus $\left(x^{\prime}, y^{\prime}, z^{\prime}\right)$ are dimensionless Cartesian coordinates, $u^{\prime}$ is dimensionless velocity, and $T^{\prime}$ is dimensionless temperature. This choice of scalings is appropriate as long as "entrance effects", i.e. very small values of $x$, are not of interest. $\tilde{U}$ is a characteristic velocity, here chosen to be the mean flow velocity. Substituting Equation (C-2) into Equation $(\mathrm{C}-1)$ yields, after rearrangement,

$$
u^{\prime} \frac{\partial T^{\prime}}{\partial x^{\prime}}=\left(\frac{1}{(R e)(P r)}\right)^{2} \frac{\partial^{2} T^{\prime}}{\partial x^{\prime 2}}+(k h)^{2} \frac{\partial^{2} T^{\prime}}{\partial y^{\prime 2}}+\frac{\partial^{2} T^{\prime}}{\partial z^{\prime 2}}+\left(\frac{\eta_{w} \tilde{U}^{2}}{q_{\mathrm{G}} h}\right)\left[(k h)^{2}\left(\frac{\partial u^{\prime}}{\partial y^{\prime}}\right)^{2}+\left(\frac{\partial u^{\prime}}{\partial z^{\prime}}\right)^{2}\right]
$$

where $(R e)=\rho_{\mathrm{w}} h \tilde{U} / \eta_{\mathrm{w}},(\operatorname{Pr})=\eta_{\mathrm{w}} c_{\mathrm{w}} / k_{\mathrm{w}}$

The dimensionless derivatives are $O(1)$, so the relative importance of the various terms is determined by the magnitude of the dimensionless constants. Consider first the factor $[(\operatorname{Re})(\operatorname{Pr})]^{-2} .(\operatorname{Pr})$, the Prandtl number, is a material constant equal to 13.7 for water at $0^{\circ} \mathrm{C}$, while the Reynolds number $(R e)$ depends upon the flow. In the steady state, melting up-glacier of a point is balanced by discharge, i.e.

$$
h \tilde{U}=M x .
$$

Therefore $(R e)=\rho_{\mathrm{w}} M x / \eta_{\mathrm{w}}$. Table C-I gives $(R e)$ for several values of $M$ and $x$. The transition to turbulent flow occurs at $(R e)=$ c. $5 \times 10^{3}$ (Stuart, [ $\left.\left.{ }^{c} 1963\right]\right)$, so sheet flow ought to be laminar for all cases considered.

If $R e>0.73$, the term $[(R e)(P r)]^{-2}<10^{-2}$, hence down-stream conduction is quite negligible compared to vertical conduction. Even for $0.23<(R e)<0.73$, the term is $<0.1$ and can still be safely neglected. It may be seen from Table $\mathrm{C}-\mathrm{I}$ that only for very short glaciers and very low melting rates will down-stream conduction need to be included in the thermal energy equation. 
TABle C-I. REYNolds NUMBER $(R e)$ FOR SUbGLACIAL SHEET Flow AS A FUNCTION OF MELTING RATE $M$ AND DISTANCE $x$ ALONG THE ICE-FLOW DIRECTION

$\underbrace{x(\mathrm{~km})}_{\mathrm{mm} \mathrm{a}^{-1}}$

15

100

2000
1

0.24

1.6

32
$(R e)$

10

24

160

3200

The factor $(k h)^{2}$ appears twice in Equation $(\mathrm{C}-3)$. Assuming that the wavelength $(=2 \pi / k)$ of water-sheet perturbations is much greater than $h, k h$ must be much less than unity; hence, terms multiplied by $(k h)^{2}$ are negligible in the overall energy balance.

Equation $(\mathrm{C}-3)$ can now be interpreted physically. Basically, geothermal heat at the bed and viscous energy losses in the water sheet are available for melting of the basal ice. Part of this energy is not conducted across the film but rather advected down-stream. Corrections for down-stream and lateral conduction are usually extremely small.

\section{ApPENDiX D. Temperature Distribution IN THE PERTURBed WATER SHEET}

The complete thermal energy equation for one-dimensional, steady, incompressible flow is (Bird and others, [ $\left.{ }^{\mathrm{c}} 1960\right]$, p. 315)

$$
\rho_{\mathrm{w}} c_{\mathrm{w}} u \frac{\partial T}{\partial x}=k_{\mathrm{w}} \nabla^{2} T+\eta_{\mathrm{w}}\left[\left(\frac{\partial u}{\partial y}\right)^{2}+\left(\frac{\partial u}{\partial z}\right)^{2}\right]
$$

where all symbols are as used in the text and defined in Appendix A. Equation (D-1) can be considerably simplified. Down-stream conduction is neglected in accordance with the results of Appendix C. Furthermore, the water temperature is assumed to differ from the pressure-melting temperature by a small enough amount for the following approximations to be valid:

$$
T=T_{\mathrm{m}}, \quad \frac{\partial T}{\partial x}=c_{\mathrm{t}} P_{\mathrm{g}} .
$$

Since $P_{g}$ has been assumed to be constant in the solution of the flow problem (Appendix B), $\partial T / \partial x$ is also constant. This is consistent with the neglect of the term in $\partial^{2} T / \partial x^{2}$. Finally, the term $(\partial u / \partial y)^{2}$ is dropped, since as shown in Appendix B, it is negligible compared to the term $(\partial u / \partial z)^{2}$. With these approximation, Equation (D-1) reduces to

$$
\gamma P_{\mathrm{g}} u=k_{\mathrm{w}}\left(\frac{\partial^{2} T}{\partial y^{2}}+\frac{\partial^{2} T}{\partial z^{2}}\right)+\eta_{\mathrm{w}}\left(\frac{\partial u}{\partial z}\right)^{2} .
$$

The term $\partial^{2} T / \partial y^{2}$ has been kept, even though small compared to the other conduction term, because cross-stream conduction might be expected to affect the sheet stability. I assume that the temperature field can be decomposed into a mean and a perturbation, viz.

$$
T(x, y, z)=T_{0}(x, z)+\varepsilon T_{1}(y, z)
$$

where $\varepsilon \ll 1$. Substituting Equation (D-4) into Equation (D-3), using Appendix B, Equation (B-11) for the term $\partial u / \partial z$, and separating terms of $O(1)$ and $O(\varepsilon)$, the following two equations are found:

$$
\begin{gathered}
k_{\mathrm{w}} \frac{\mathrm{d}^{2} T_{0}}{\mathrm{~d} z^{2}}=\frac{\gamma P_{\mathrm{g}}^{2}}{2 \eta_{\mathrm{w}}}\left(-z^{2}+h z\right)+\frac{P_{\mathrm{g}}^{2}}{\eta_{\mathrm{w}}}\left(-z^{2}+h z-\frac{h^{2}}{4}\right), \\
k_{\mathrm{w}}\left(\frac{\partial^{2} T_{1}}{\partial y^{2}}+\frac{\partial^{2} T_{1}}{\partial z^{2}}\right)=\frac{\gamma P_{\mathrm{g}}^{2} h^{2}}{2 \eta_{\mathrm{w}} \sinh k h} \sin k y \sinh k z+\frac{P_{\mathrm{g}}^{2} k h^{2}}{2 \eta_{\mathrm{w}} \sinh k h}(2 z-h) \sin k y \cosh k z .
\end{gathered}
$$

The boundary conditions on the temperature are

$$
T\left(z_{0}\right)=T_{\mathrm{m}}(x)=-c_{\mathrm{t}} p(x),
$$




$$
-k_{\mathrm{w}} \frac{\partial T}{\partial z}(z=0)=q_{\mathrm{G}} .
$$

Since $p(x)=p(x=0)-P_{\mathrm{g}} x$, Equation (D-7a) can be rewritten as

$$
T\left(z=z_{0}\right)=T_{\mathrm{m} 0}+C_{\mathrm{t}} P_{\mathrm{g}} x
$$

where $T_{\mathrm{m} 0}=-c_{\mathrm{t}} P(x=0)$ is the pressure-melting temperature at $x=0$. Equation (D-5) can be integrated with respect to $z$ to yield

$$
T_{0}=\frac{\gamma P_{\mathrm{g}}^{2}}{2 \eta_{\mathrm{w}} k_{\mathrm{w}}}\left(-\frac{z^{4}}{12}+\frac{h z^{3}}{6}\right)+\frac{P_{\mathrm{g}}^{2}}{\eta_{\mathrm{w}} k_{\mathrm{w}}}\left(-\frac{z^{4}}{12}+\frac{h z^{3}}{6}-\frac{h^{2} z^{2}}{8}\right)+C_{0}(x) z+C_{1}(x)
$$

where $C_{0}(x)$ and $C_{1}(x)$ are, in general, functions of $x$ to be evaluated by use of boundary conditions.

The temperature perturbation $T_{1}$ will have the form

$$
T_{1}=F(z) \cosh k z \sin k y+G(z) \sinh k z \sin k y
$$

where $F(z)$ and $G(z)$ are chosen to satisfy Equation (D-6). Substituting Equation (D-9) into (D-6), one finds

$$
\begin{aligned}
& F(z)=f_{0}-\frac{P_{\mathrm{g}}^{2} h^{2}(1-\gamma)}{4 \eta_{\mathrm{w}} k_{\mathrm{w}} k \sinh k h} z, \\
& G(z)=g_{0}+\frac{P_{\mathrm{g}}^{2} h^{2}}{4 \eta_{\mathrm{w}} k_{\mathrm{w}} \sinh k h}\left(z^{2}-h z\right),
\end{aligned}
$$

where $f_{0}$ and $g_{0}$ are constants to be determined.

The evaluation of $C_{0}(x), C_{1}(x), f_{0}$, and $g_{0}$ is extremely tedious, involving lengthy algebraic manipulations. I present here only their values:

$$
\begin{aligned}
C_{0}(x) & =-\frac{q_{\mathrm{G}}}{k_{\mathrm{w}}}, \\
C_{1}(x) & =\frac{q_{\mathrm{G}} h}{k_{\mathrm{w}}}+\frac{P_{\mathrm{g}}^{2} h^{4}(1-\gamma)}{24 \eta_{\mathrm{w}} k_{\mathrm{w}}}+T_{\mathrm{m} 0}+c_{\mathrm{t}} P_{\mathrm{g}} x, \\
f_{0} & =\frac{q_{\mathrm{G}} h}{k_{\mathrm{w}} \cosh k h}+\frac{P_{\mathrm{g}}^{2} h^{4}(1-\gamma)}{12 \eta_{\mathrm{w}} k_{\mathrm{w}} \cosh k h}-\frac{P_{\mathrm{g}}^{2} h^{2}(1-\gamma)}{4 \eta_{\mathrm{w}} k_{\mathrm{w}} k^{2} \cosh k h}+\frac{P_{\mathrm{g}}^{2} h^{3}(1-\gamma)}{4 \eta_{\mathrm{w}} k_{\mathrm{w}} k \sinh k h}, \\
g_{0} & =\frac{P_{\mathrm{g}}^{2} h^{2}(1-\gamma)}{4 \eta_{\mathrm{w}} k_{\mathrm{w}} k^{2} \sinh k h} .
\end{aligned}
$$

The heat flux at the ice-water interface can now be found by substituting the expressions (D-11) into Equations (D-8) and (D-9), computing the derivatives $\partial T_{0} / \partial z$ and $\partial T_{1} / \partial z$, and evaluating at $z=z_{0}$. The resultant heat flux $Q z_{0}$ can be shown to be

$$
Q_{z_{0}}=-k_{\mathrm{w}} \frac{\partial T}{\partial z}\left(z_{0}\right)=q_{\mathrm{G}}+\frac{P_{\mathrm{g}}^{2} h^{3}(1-\gamma)}{12 \eta_{\mathrm{w}}}-\left\{q_{\mathrm{G}} k h \tanh k h+\frac{P_{\mathrm{g}}^{2} h^{3}(1-\gamma) \tanh k h}{4 \eta_{\mathrm{w}}}\left(\frac{k h}{3}-\frac{1}{k h}\right)\right\} .
$$

If $k h \ll 1$, this can be rewritten by using the expansion of $\tanh k h$ for small $k h: \tanh k h=k h-k^{3} h^{3} / 3+O\left(k^{5} h^{5}\right)$. With this approximation, the heat flux $Q z_{0}$ can be written in the form of Equation (15) of the main text.

\section{APPENDiX E. Viscous RELAXATION OF THE ICE-WATER INTERFACE}

Sagging of the basal ice when the ice-water interface is perturbed is analyzed by the method of Fletcher (1977). Both ice and water are assumed to be incompressible, linear-viscous fluids. The unperturbed state is hydrostatic equilibrium. Imposition of a gentle waviness on the interface results in small changes in the stress state in the fluids, which flow quasi-statically in response to the altered stress condition. The stresses and velocities associated with the 
perturbation can be written in a form analogous to Fletcher's equations $(17 \mathrm{a}-\mathrm{d})$ :

$$
\begin{aligned}
\tilde{\sigma}_{z z} & =2 \eta_{\mathrm{f}} k\left\{\left[A^{\prime}+B^{\prime} k(h-z)\right] \mathrm{e}^{k(h-z)}-\left[C^{\prime}+D^{\prime} k(h-z)\right] \mathrm{e}^{-k(h-z)}\right\} \sin k y, \\
\tilde{\sigma}_{y z} & =-2 \eta_{\mathrm{f}} k\left\{\left[A^{\prime}+B^{\prime}(1+k h-k z)\right] \mathrm{e}^{k(h-z)}+\left[C^{\prime}-D^{\prime}(1-k h+k z)\right] \mathrm{e}^{k(h-z)}\right\} \cos k y, \\
v_{\mathrm{f}} & =-\left\{\left[A^{\prime}+B^{\prime}(1+k h-k z)\right] \mathrm{e}^{k(h-z)}-\left[C^{\prime}-D^{\prime}(1-k h+k z)\right] \mathrm{e}^{-k(h-z)}\right\} \cos k y, \\
w_{\mathrm{f}} & =\left\{\left[A^{\prime}+B^{\prime} k(h-z)\right] \mathrm{e}^{k(h-z)}+\left[C^{\prime}+D^{\prime} k(h-z)\right] \mathrm{e}^{-k(h-z)}\right\} \sin k y,
\end{aligned}
$$

where $v_{\mathrm{f}}$ and $w_{\mathrm{f}}$ are velocities in the $y$ and $z$ directions, respectively, the interface is at $z_{0}(y)=h+A \sin k y$, and the slope $k A \ll 1 . A^{\prime}, B^{\prime}, C^{\prime}, D^{\prime}$ are integration constants, and $\eta_{\mathrm{f}}$ is the fluid viscosity. Equations (E-1) are exact to $O(k A)$. One such set of four equations can be written for each fluid. The boundary conditions used to determine the total of eight integration constants can be stated as follows:

(i) Normal and shear stresses and normal velocities in the two fluids must match at $z=z_{0}(y)$,

(ii) $v=w=0$ in the water on $z=0$,

(iii) $v \rightarrow 0, w \rightarrow 0$ in the ice as $z \rightarrow \infty$.

The problem of determining the integration constants can be reduced to the solution of a system of four simultaneous algebraic equations. These equations are solved by standard, though tedious techniques.

Due to the extreme viscosity contrast between ice and water, the solution effectively reduces to that for the relaxation of perturbation on a free surface of ice. The quantities of most interest, the velocities, can be expressed to an excellent approximation as

$$
\begin{aligned}
& v_{\mathrm{p}}=-\frac{\left(\rho_{\mathrm{w}}-\rho_{\mathrm{i}}\right) g A}{2 \eta_{\mathrm{i}} k} k(h-z) \mathrm{e}^{k(h-z)} \cos k y, \\
& w_{\mathrm{p}}=-\frac{\left(\rho_{\mathrm{w}}-\rho_{\mathrm{i}}\right) g A}{2 \eta_{\mathrm{i}} k}[1-k(h-z)] \mathrm{e}^{k(h-z)} \sin k y,
\end{aligned}
$$

where $v_{\mathrm{p}}$ and $w_{\mathrm{p}}$ are the velocities in the ice and $\eta_{\mathrm{i}}$ is the effective ice viscosity. On the interface $z=z_{0}(y)$ these reduce to

$$
\begin{aligned}
& v_{\mathrm{p}}=\frac{\left(\rho_{\mathrm{w}}-\rho_{\mathrm{i}}\right) g A}{2 \eta_{\mathrm{i}} k}(k A \sin k y) \cos k y+O\left(k^{2} A^{2}\right) \\
& w_{\mathrm{p}}=-\frac{\left(\rho_{\mathrm{w}}-\rho_{\mathrm{i}}\right) g A}{2 \eta_{\mathrm{i}} k} \sin k y+O\left(k^{2} A^{2}\right),
\end{aligned}
$$

where I have expanded the exponentials as power series in $k A$. Equations (E-3) are the result used in the main text.

\section{REFERENCES}

Berner, W., and others. 1978. Dynamic glacier flow model and the production of internal meltwater, by W. Berner, B. Stauffer, and H. Oeschger. Zeitschrift für Gletscherkunde und Glazialgeologie, Bd. 13, Ht. 1-2, 1977, p. 209-17.

Bird, R. B., and others [ ${ }^{c} 1960$.] Transport phenomena, by R. B. Bird, W. E. Stewart, and E. N. Lightfoot. New York, etc., John Wiley and Sons, Inc.

Engelhardt, H. F. 1978. Water in glaciers: observations and theory of the behaviour of water levels in boreholes. Zeitschrift für Gletscherkunde und Glazialgeologie, Bd. 14, Ht. 1, p. 35-60.

Fletcher, R. C. 1977. Folding of a single viscous layer: exact infinitesimal-amplitude theory. Tectonophysics, Vol. 39, No. 4, p. 593-606.

Hallet, B. 1979. Subglacial regelation water film. Journal of Glaciology, Vol. 23, No. 89, p. 321-34.

Hallet, B., and Anderson, R. S. In press. Detailed glacial geomorphology of a proglacial bedrock area at Castleguard Glacier. Zeitschrift für Gletscherkunde und Glazialgeologie.

Hodge, S. M. 1974. Variations in the sliding of a temperate glacier. Journal of Glaciology, Vol. 13, No. 69, p. 349-69.

Hodge, S. M. 1976. Direct measurement of basal water pressures: a pilot study. Journal of Glaciology, Vol. 16, No. 74 , p. $205-18$. 
Hodge, S. M. 1979. Direct measurement of basal water pressures: progress and problems. Journal of Glaciology, Vol. 23, No. 89, p. 309-19.

Iken, A., and others. 1979. The uplift of Unteraargletscher at the beginning of the melt season-a consequence of water storage at the bed? By A. Iken, A. Flotron, W. Haeberli, and H. Röthlisberger. Journal of Glaciology, Vol. 23, No. 89, p. 430-32. [Abstract.]

Lliboutry, L. A. 1978. Glissement d'un glacier sur un plan parsemé d'obstacles hémisphériques. Annales de Géophysique, Tom. 34, No. 2, p. 147-62.

Lliboutry, L. A. 1979. Local friction laws for glaciers: a critical review and new openings. Journal of Glaciology, Vol. 23, No. 89, p. 67-95.

Mathews, W. H. 1964. Water pressure under a glacier. Journal of Glaciology, Vol. 5, No. 38, p. $235-40$.

Mathews, W. H. 1973. Record of two jökullhlaups. Union Géodésique et Géophysique Internationale. Association Internationale d'Hydrologie Scientifique. Commission de Neiges et Glaces. Symposium on the Hydrology of Glaciers, Cambridge, 7-13 September 1969, p. 99-110. (Publication No. 95 de l'Association Internationale d'Hydrologie Scientifique.)

Meier, M. F. 1965. Comments on Paterson's paper, "Variations in velocity of Athabasca Glacier with time". Journal of Glaciology, Vol. 5, No. 41, p. 761-62. [Letter.]

Meier, M. F., and Post, A. S. 1969. What are glacier surges? Canadian Journal of Earth. Sciences, Vol. 6, No. 4, Pt. 2, p. 807-17.

Nye, J. F. 1973. Water at the bed of a glacier. Union Geodesique et Géophysique Internationale. Association Internationale d'Hydrologie Scientifique. Commission de Neiges et Glaces. Symposium on the Hydrology of Glaciers, Cambridge, 7-13 September 1969, p. 189-94. (Publication No. 95 de l'Association Internationale d'Hydrologie Scientifique.)

Nye, J. F. 1976. Water flow in glaciers: jökulhlaups, tunnels, and veins. Journal of Glaciology, Vol. 17, No. 76, p. 181-207.

Nye, J. F., and Frank, F. C. 1973. Hydrology of the intergranular veins in a temperate glacier. Union Géodésique et Géophysique Internationale. Association Internationale d'Hydrologie Scientifique. Commission de Neiges et Glaces. Symposium on the Hydrology of Glaciers, Cambridge, 7-13 September 1969, p. 157-61. (Publication No. 95 de l'Association Internationale d'Hydrologie Scientifique.)

Raymond, C. F., and Harrison, W. D. 1975. Some observations on the behavior of the liquid and gas phases in temperate glacier ice. Journal of Glaciology, Vol. 14, No. 71, p. 213-33.

Röthlisberger, H. 1972. Water pressure in intra- and subglacial channels. Journal of Glaciology, Vol. 11, No. 62, p. 177-203.

Röthliskberger, H., and others. 1979 Piezometric observations of water pressure at the bed of Swiss glaciers, by H. Röthlisberger, A. Iken, and U. Spring, Journal of Glaciology, Vol. 23, No. 89, p. 429-30. [Abstract.]

Shreve, R. L. 1972. Movement of water in glaciers. Journal of Glaciology, Vol. 11, No. 62, p. $205-14$.

Stenborg, T. 1969. Studies of the internal drainage of glaciers. Geografiska Annaler, Vol. 51 A, Nos. 1-2, p.13-41.

Stenborg, T. 1973. Some viewpoints on the internal drainage of glaciers. Union Géodésique et Géophysique Internationale. Association Internationale d'Hydrologie Scientifique. Commission de Neiges et Glaces. Symposium on the Hydrology of Glaciers, Cambridge, 7-13 September 1969, p 117-29. (Publication No. 95 de l'Association Internationale d'Hydrologie Scientifique.)

Stuart, J. T. [' $\left.{ }^{c} 1963.\right]$ Hydrodynamic stability. (In Rosenhead, L., ed. Laminar boundary layers. Oxford, Clarendon Press, p. 492-579.)

Vivian, R. A., and Zumstein, J. 1973. Hydrologie sous-glaciaire au glacier d'Argentière (Mont-Blanc, France). Union Géodésique et Géophysique Internationale. Association Internationale d'Hydrologie Scientifique. Commission de Neiges et Glaces. Symposium on the Hydrology of Glaciers, Cambridge, 7-13 September 1969, p. 53-64. (Publication No. 95 de l'Association Internationale d'Hydrologie Scientifique.)

Walder, J., and Hallet, B. 1979. Geometry of former subglacial water channels and cavities. Journal of Glaciology, Vol. 23, No. 89, p. 335-46.

Watts, P. A. Unpublished. Inclusions in ice. [Ph.D. thesis, University of Bristol, 1974.]

Weertman, J. 1957. On the sliding of glaciers. Journal of Glaciology, Vol. 3, No. 21, p. 33-38.

Weertman, J. 1962. Catastrophic glacier advances. Union Gèodésique et Géophysique Internationale. Association Internationale d'Hydrologie Scientifique. Commission des Neiges et des Glaces. Colloque d'Obergurgl, 10-9_18-9 1962, p. 31-39. (Publication No. 58 de l'Association Internationale d'Hydrologie Scientifique.)

Weertman, J. 1964. The theory of glacier sliding. Journal of Glaciology, Vol. 5, No. 39, p. 287-303.

Weertman, J. 1966. Effect of a basal water layer on the dimensions of ice sheets. Journal of Glaciology, Vol. 6, 
No. 44, p. 191-207.

Weertman, J. 1969. Water lubrication mechanism of glacier surges. Canadian Journal of Earth Sciences, Vol. 6, No. 4, Pt. 2, p. 929-42.

Weertman, J. 1972. General theory of water flow at the base of a glacier or ice sheet. Reviews of Geophysics and Space Physics, Vol. 10, No. 1, p. 287-333.

Weertman, J. 1973. Can a water-filled crevasse reach the bottom surface of a glacier? Union Géodésique et Geophysique Internationale. Association Internationale d'Hydrologie Scientifique. Commission de Neiges et Glaces. Symposium on the Hydrology of Glaciers, Cambridge, 7-13 September 1969, p. 139-45. (Publication No. 95 de l'Association Internationale d'Hydrologie Scientifique.) 